\title{
Feasibility study of sustained-release travoprost punctum plug for intraocular pressure reduction in an Asian population
}

This article was published in the following Dove Press journal:

Clinical Ophthalmology

26 April 2016

Number of times this article has been viewed

\author{
Shamira A Perera ${ }^{1-3}$ \\ Daniel SW Ting ${ }^{1,2}$ \\ Monisha E Nongpiur ${ }^{1-3}$ \\ Paul T Chew ${ }^{3}$ \\ Maria Cecilia D Aquino ${ }^{3}$ \\ Chelvin CA Sng ${ }^{3}$ \\ Sue-Wei Hol,2 \\ Tin Aung ${ }^{1-3}$ \\ 'Singapore Eye Research Institute, \\ Singapore; ${ }^{2}$ Singapore National Eye \\ Centre, Singapore; ${ }^{3}$ Department of \\ Ophthalmology, Yong Loo Lin School \\ of Medicine, National University of \\ Singapore, Singapore
}

Purpose: To investigate the efficacy and safety of a punctum plug-based sustained drug release system for a prostaglandin analog, travoprost (OTX-TP), for intraocular pressure (IOP) reduction in an Asian population.

Methods: This is an initial feasibility, prospective, single-arm study involving 26 eyes and a bioresorbable punctum plug containing OTX-TP. An OTX-TP was placed in the vertical portion of the superior or inferior canaliculus of patients with primary open-angle glaucoma or ocular hypertension. The main outcome measure was the IOP-lowering efficacy of OTX-TP at 3 ( 8 am) and 10, 20, and 30 days ( $8 \mathrm{am}, 10 \mathrm{am}$, and $4 \mathrm{pm}$ ), compared to baseline.

Results: A total of 26 OTX-TP were inserted for 17 subjects. The mean (standard deviation) age was 57.2 (13.8) years. At 10 days, all plugs were still present, and the IOP reduction from baseline was $6.2(23 \%), 5.4(21 \%)$, and $7.5 \mathrm{mmHg}(28 \%)$ at $8 \mathrm{am}, 10 \mathrm{am}$, and $4 \mathrm{pm}$, respectively. At 10 days, the mean IOP (standard error of mean) was 21.2 (1.2), 20.4 (0.8), and 19.7 (1.0) at $8 \mathrm{am}, 10 \mathrm{am}$, and $4 \mathrm{pm}$, respectively, showing no discernible IOP trend during the course of the day. At 30 days, plug retention had declined to $42 \%$, and the overall IOP reduction had decreased to $16 \%$.

Conclusion: The sustained-release OTX-TP is able to reduce IOP by $24 \%$ (day 10 ) and $15.6 \%$ (day 30), respectively. It is a potentially well-tolerable ocular hypotensive for glaucoma patients with a history of poor compliance.

Keywords: ocular hypertension, travoprost, bioresorbable, punctum plug, glaucoma, Asian

\section{Introduction}

The primary goal of glaucoma treatment is to prevent progressive visual field loss by lowering intraocular pressure (IOP). The success of medical therapy of glaucoma patients thus depends largely on patients' adherence and persistency to the medication. The noncompliance rate in glaucoma patients was reported to be as high as $59 \%$ in a systematic review. ${ }^{1}$ The reasons for poor compliance to topical medications can be due to difficulty in administering eye drops, complex treatment regimes, poor comprehension on the part of patients, lack of confidence in their ophthalmologist's advice, and simple forgetfulness. ${ }^{2}$ Furthermore, studies on persistency, which measure prescription refills and refill times, have shown that less than $50 \%$ of glaucoma subjects continue therapy and refill prescriptions as required. ${ }^{3}$ A pharmacy study has reported persistency to be lower in the Singapore population compared to that previously reported in Caucasians, being $11.5 \%$ after 3 years. ${ }^{4}$ Suboptimal medical management of glaucoma due to poor adherence and persistence can lead to a greater socioeconomic burden of blindness, which has implications for patients and health care systems. ${ }^{5}$
Correspondence: Shamira A Perera Singapore National Eye Centre, II Third Hospital Avenue, Singapore 168751

Tel +65 62277255

Fax +6562263395

Email shamira.perera@snec.com.sg (c) (1) (9) 2016 Perera et al. This work is published and licensed by Dove Medical Press Limited. The full terms of this license are available at https://www.dovepress.com/terms.php BY NC and incorporate the Creative Commons Attribution - Non Commercial (unported, v3.0) License (http:///creativecommons.org/licenses/lby-nc/3.0/). By accessing the work you
hereby accept the Terms. Non-commercial uses of the work are permitted without any further permission from Dove Medical Press Limited, provided the work is properly attributed. For permission for commercial use of this work, please see paragraphs 4.2 and 5 of our Terms (https://www.dovepress.com/terms.php). 
Travoprost is a prostaglandin analog that can reduce the mean IOP from $25 \%$ to $32 \%$ and can be sustained throughout the 24-hour cycle..$^{6-8}$ The travoprost punctum plug (OTX-TP) is a novel sustained-release travoprost delivery system that consists of a rod-shaped, dried polyethylene glycol-based hydrogel punctum plug designed to be placed in the vertical portion of the superior or inferior canaliculus. Embedded in the punctum plug are poly(lactic acid) microspheres which contain encapsulated travoprost, the active pharmaceutical ingredient. As the OTX-TP hydrates in the tear fluid within the canaliculus, it swells in volume to fill the potential space. The microspheres, which are bioresorbable particles, slowly degrade via hydrolysis and gradually release the drug in a controlled fashion over a period of 30 days. The retention and placement of OTX-TP can be identified by the presence of the color additive D\&C Violet No 2, which serves as a visualization aid.

The purpose of this study was to evaluate the safety and efficacy of the OTX-TP in patients with primary open-angle glaucoma and ocular hypertension (OHT) over 30 days.

\section{Methods}

This was a prospective, single-arm feasibility study conducted at two centers in Singapore (the Singapore National Eye Center and National University Hospital, Singapore). The study was approved by the respective institutional review boards and conducted in accordance with the Declaration of Helsinki. The study also had the approval of the Clinical
Trials Section of the Health Sciences Authority of Singapore. Written informed consent was obtained from all subjects.

To assess for eligibility, participants underwent a standardized interview and eye examination that included visual acuity measurement using a logarithm of minimum angle of resolution chart (LogMAR; Lighthouse, Inc., Long Island, NY, USA), slit-lamp examination (Model BQ 900; HAAG-STREIT, Bern, Switzerland), stereoscopic optic disc examination with a 78-diopter lens (Volk Optical, Inc, Mentor, OH, USA), and gonioscopy, performed in the dark using a Goldmann 2-mirror lens (HAAG-STREIT) at high magnification (X16).

The inclusion and exclusion criteria of our study are listed in Table 1. Primary open-angle glaucoma was defined as glaucomatous optic neuropathy (highlighted by a cup:disc ratio of $>0.7$, and/or the presence of neuroretinal rim notching) with a compatible visual field defect and open angles on gonioscopy, while OHT patients had normal optic discs and visual fields, and open angles. A threshold examination of the central $24^{\circ}$ of visual field (SITA 24-2 program; Carl Zeiss Meditec, Dublin, CA, USA), showing a glaucoma hemifield test "outside normal limits", and a cluster of three contiguous points on the pattern deviation plot depressed at $P<5 \%$ level of occurring in age-matched normal subjects and not crossing the horizontal meridian, were considered compatible with glaucoma. Test reliability was determined if the following criteria were satisfied: fixation loss $<20 \%$; false-positive $<33 \%$; and/or false-negative $<33 \%$. ${ }^{9}$

Table I The inclusion and exclusion criteria of our study patients

\section{Inclusion criteria}

- Patients' age $\geq 21$ with ocular hypertension or open-angle glaucoma and not on active glaucoma treatment

- Patients with IOP of $\geq 24$ and $\leq 34 \mathrm{mmHg}$ in each eye, at baseline (day 0 ) hour $0\left(T_{0}\right)$; and IOP of $\geq 22$ and $\leq 34 \mathrm{mmHg}$ in each eye in $2 \mathrm{~h}\left(T_{0}+2 \mathrm{~h}\right.$ ) and $8 \mathrm{~h}$ time $\left(T_{0}+8 \mathrm{~h}\right)$

- Patients with BCVA of 0.6 logMAR (20/80 Snellen) or better in each eye as measured using an ETDRS chart

Exclusion criteria

- Known or suspected allergy to travoprost or to any component of the study product

- IOP of $>34 \mathrm{mmHg}$ in either eye at any time point during study period

- $\mathrm{CCT}<460$ or $>620 \mu \mathrm{m}$

- Patients with advanced glaucomatous changes, including cup-to-disc ratio $>0.80$ (horizontal or vertical measurement, severe central visual field loss, or documented significant progression of a visual field defect during the recruitment period)

- Difficulty of OTX-TP insertion due to presence of punctum or lacrimal drainage (canaliculus, lacrimal sac, nasolacrimal duct) anomalies

- History of inadequate response to treatment with prostaglandins

- History of ocular trauma, laser surgery, or previous intraocular surgery within the past 6 months in either eye

- History of ocular infection or ocular inflammation within 3 months prior to the study in either eye, severe dry eyes, active epiphora, active blepharitis, aniridia, retinal detachment, and diabetic retinopathy

- Use of any topical glaucoma or nonglaucoma eye drops or systemic ocular hypertensive medication at baseline or during the study period

- Use of any systemic corticosteroids (not including inhaled or nasal steroids) within 4 weeks prior to the study

- Use of contact lenses at any point during the study

- Pregnant or breast-feeding women or women who wish to become pregnant during the time of study participation

- Any subject is deemed not to be suitable by the clinician for reasons not already specified (eg, systemic or other ocular disease/abnormality)

Abbreviations: IOP, intraocular pressure; BCVA, best corrected visual acuity; CCT, central corneal thickness; OTX-TP, travoprost punctum plug; ETDRS, Early Treatment Diabetic Retinopathy Study; logMAR, logarithm of the minimum angle of resolution. 
All patients who met the inclusion and exclusion criteria were recruited at the screening visit (Visit 1). Patients on previous treatment with topical antiglaucoma drops were required to complete a minimum washout period, before OTX-TP insertion at the subsequent visit (Visit 2, baseline visit), as follows: 4 weeks for $\beta$-adrenergic blockers and prostaglandin analogs, 3 weeks for $\alpha$-adrenergic blockers, and 7 days for pilocarpine or carbonic anhydrase inhibitors.

At the baseline visit, IOP was recorded at $8 \mathrm{am}, 10 \mathrm{am}$, and $4 \mathrm{pm}$; and the OTX-TP was inserted for eligible patients after the $4 \mathrm{pm}$ IOP assessment (between 4 and 4:30 pm). The OTX-TP was inserted into either the superior or inferior vertical canaliculus of each subject's eligible eye(s), depending on ease of insertion. The patients were subsequently followed up on day-3 (IOP check at 8 am), day-10 (IOP check at 8 am, $10 \mathrm{am}$, and $4 \mathrm{pm}$ ), day-20 (IOP check at $8 \mathrm{am}, 10 \mathrm{am}$, and $4 \mathrm{pm}$ ), and day-30 (IOP check at $8 \mathrm{am}, 10 \mathrm{am}$, and $4 \mathrm{pm}$ ). A day-34 visit was conducted at 8 am as a postremoval safety check before the patient exited the study.

All IOP measurements were performed using Goldmann applanation tonometry (GAT; HAAG-STREIT) by two qualified ophthalmologists. This process was masked in that one observer would measure the IOP and the second person would read the IOP off the tension knob of the tonometer. Two measurements were performed in each eye at each time point, and the mean of these measurements was used in the analyses. In addition, at each study visit, the participants underwent an evaluation that included measurement of visual acuity, systemic blood pressure and pulse rate, and a slitlamp examination to assess for hyperemia and for retention of the OTX-TP. Hyperemia was graded from Grades 1 to 3 by comparison with standardized photographs. ${ }^{10}$

For an eligible subject with both eyes that met the eligibility criteria, the OTX-TP was inserted in both eyes, but only the eye with the higher baseline IOP was included in the analysis. If a subject had bilateral glaucoma or OHT, but only one eye met the criteria, the eligible eye was treated with the OTX-TP, while the fellow eye was continued on the previous topical antiglaucoma medication.

For the assessment of OTX-TP presence in the canaliculus, a handheld transilluminator torch was used to find any rodshaped shadow deep in the canal. Slit-lamp biomicroscopy was also used to assess for the presence of the more superficially placed OTX-TP through direct visualization down the punctum.

All subjects were actively monitored for comfort, ocular complaints, and postinsertion adverse ocular events throughout the study period. An adverse event was defined as any undesirable event occurring in a subject regardless of whether it was considered related to the investigational drug. A serious adverse event was defined as an event that was potentially fatal, life threatening, permanently disabling, requiring hospitalization, or requiring intervention to prevent permanent impairment or damage.

\section{Statistical analyses}

The analyses for the outcome measures used all available data for each study visit on an intent-to-treat (ITT) basis. Predetermined time points for the study included results at days 3, 10, 20, and 30. To adjust for the possible effect of missing data on the study results, the analysis of mean changes for IOP was performed using the single imputation methods of last-value carried forward.

The primary outcome measure of our study was IOPlowering efficacy (defined as the mean IOP reduction at $8 \mathrm{am}$, $10 \mathrm{am}$, and $4 \mathrm{pm}$ on day 30 post-OTX-TP insertion), while the secondary outcome measure was the retention rate and tolerability of OTX-TP at day 30. Data were described in terms of mean \pm standard deviation for continuous variables and as frequencies and percentages for categorical variables. Wilcoxon signed ranks paired test was used to assess the mean changes in IOP from baseline at each individual time point. An appropriate Bonferroni correction $(\alpha / 5)$ was applied to correct for the number of time points evaluated, resulting in a $P$-value threshold of 0.01 to be considered statistically significant. If both eyes were eligible for analysis, the eye with the higher baseline IOP reading was used. As this was a feasibility study, no formal sample size estimation was performed. Statistical analysis was performed using the statistical package SPSS Version 17 (SPSS, Chicago, IL, USA).

\section{Results}

A total of 17 subjects were recruited and included in the ITT analysis. The mean (standard deviation) age was 57.2 (13.8) years and the majority of the subjects were male (76\%) and Chinese (65\%) (Table 2). Figure 1 shows the subject

Table 2 Demographics of the study population

\begin{tabular}{ll}
\hline Age, years & \\
Mean (SD) & $57.24(13.8)$ \\
Median & 58.0 \\
Min-max & $24-75$ \\
Sex & $\mathrm{N}(\%)$ \\
Male & $13(0.76)$ \\
Female & $4(0.24)$ \\
Race & $\mathrm{N}(\%)$ \\
Chinese & $\mathrm{II}(65)$ \\
Malay & $\mathrm{I}(6)$ \\
Indian & $5(29)$ \\
\hline
\end{tabular}

Abbreviation: SD, standard deviation. 


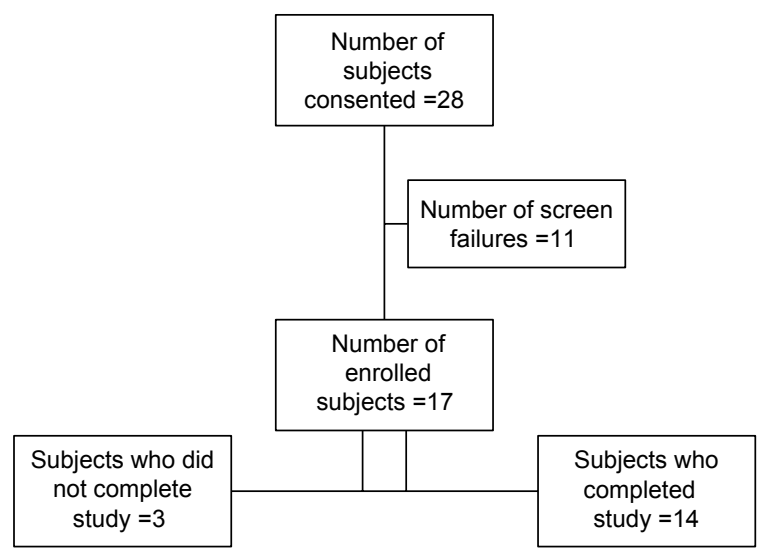

Figure I Subject disposition.

disposition of our study. For the 17 subjects who were recruited for the trial, 26 OTX-TP were inserted. However, the higher IOP eye was selected for the IOP analysis, and so seven right eyes and ten left eyes were finally considered for the study.

In our study, more than three-quarters of OTX-TP $(77 \%$, $\mathrm{n}=20$ ) were deemed to be "easy to insert" by the operator. Of the 26 OTX-TP, most patients tolerated them well, except for one patient who developed bilateral severe epiphora, requiring removal and reinstitution of topical ocular hypotensives on day 1. Subsequently, glaucoma medication was also restarted in two other subjects due to plug extrusion (day 10, IOP $26 \mathrm{mmHg}$ ) and inadequate IOP control (day 20, IOP $29 \mathrm{mmHg}$ ). The last observed IOP readings prior to the institution of therapy were carried forward in the ITT analysis.

Table 3 shows the mean IOP at 8 am, 10 am, and 4 pm at baseline visit and at days 3, 10, 20, and 30; Figure 2 illustrates the mean IOP at each study visit and time point. Following OTX-TP insertion, there was a statistically significant reduction in mean IOP at all study visits ( $P$-value $<0.01$ for all), with the greatest drop in IOP observed at day 10 (Table 4 and Figure 3). The mean reduction in IOP was 5.4, 6.4, 4.7, and $4.3 \mathrm{mmHg}$ at days $3,10,20$, and 30 , respectively. This corresponded to a percentage drop of $20.3 \%, 24 \%, 17 \%$, and $15.6 \%$, respectively (Table 4 and Figure 3), which appeared to show a trend corresponding to plug retention, although no statistically significant differences in IOP measurements were noted. The comparable IOP reduction at days 10, 20, and 30 ( $P>0.05$ for all pairwise comparisons, data not shown) at each visit suggested a sustained effect of the drug. Table 5 shows the percentage of eyes achieving target IOP at various follow-up visits.

At day 20, (21/24) 87.5\% OTX-TP were visible, and this dropped to $(11 / 24), 41.7 \%$ at day 30 (Table 6). The peak ocular complaint rate occurred at 3 days; these were foreign body sensation $(38.5 \%, \mathrm{n}=10)$, itchiness $(15.4 \%$, $n=4)$, epiphora $(3.8 \%, n=1)$, and ocular pain $(3.8 \%, n=1)$. As a consequence of severe intolerance secondary to epiphora, two OTX-TP from a single patient necessitated removal early in enrollment. The tolerability of the OTX-TP improved subsequently, with only one patient experiencing epiphora and two patients experiencing eye itchiness (Table 7).

\section{Discussion}

This study found a sustained IOP-lowering effect due to the OTX-TP over 30 days, combined with a reasonable safety profile and low nonresponder rate. The peak effect (24\%) was observed at day 10 while $100 \%$ of the plugs were still present. The effect appeared to tail off by day 30 as the plug retention rate declined. The mean IOP at the 3, 10, 20, and 30-day time points was $21.4,20.4,22.1$, and $22.5 \mathrm{mmHg}$, respectively, and these reduced from a baseline of $26.8 \mathrm{mmHg}$. Only two subjects required commencement of topical IOP-lowering therapy, one due to inadequate IOP control and the other as the OTX-TP had extruded on day 10.

After insertion, all plugs could be visualized directly, with the majority not even needing slit-lamp magnification to see the OTX-TP. Retention of the plug (by visualization) was $100 \%$ through 10 days, then retention declined to day 30 , with $42 \%$ of the punctum plugs deemed still visible. This may be an underestimate; the violet colorant dissipated over time and the inability of transillumination to detect a small remnant of the OTX-TP may be one of the potential reasons for such a low retention by visualization. As there was still significant

Table 3 Mean IOP at various time-points during the 30-day study period

\begin{tabular}{|c|c|c|c|c|c|c|c|c|c|c|c|c|c|}
\hline \multirow[t]{2}{*}{ Visit day } & \multicolumn{3}{|c|}{ Day 0 (baseline) } & \multirow{2}{*}{$\frac{\text { Day } 3}{8 \text { am }}$} & \multicolumn{3}{|l|}{ Day 10} & \multicolumn{3}{|l|}{ Day 20} & \multicolumn{3}{|l|}{ Day 30} \\
\hline & 8 am & $10 \mathrm{am}$ & $4 \mathrm{pm}$ & & $8 \mathrm{am}$ & $10 \mathrm{am}$ & 4 pm & $8 \mathrm{am}$ & $10 \mathrm{am}$ & $4 \mathrm{pm}$ & 8 am & $10 \mathrm{am}$ & 4 pm \\
\hline Mean & 27.4 & 25.8 & 27.2 & 21.4 & 21.2 & 20.4 & 19.7 & 22.5 & 21.6 & 22.3 & 23.8 & 21.7 & 21.9 \\
\hline SD & 2.7 & 3.0 & 3.6 & 5.1 & 5.1 & 3.5 & 4.0 & 6.4 & 3.8 & 6.5 & 6.0 & 4.2 & 5.0 \\
\hline SEM & 0.7 & 0.7 & 0.9 & 1.3 & 1.2 & 0.8 & 1.0 & 1.5 & 0.9 & 1.6 & 1.5 & 1.0 & 1.2 \\
\hline $95 \% \mathrm{Cl}$ & $2.0,4.1$ & $2.2,4.5$ & $2.7,5.5$ & $3.8,7.9$ & $3.8,7.8$ & $2.6,5.3$ & $3.0,6.1$ & $4.8,9.7$ & $2.8,5.8$ & $4.8,9.9$ & $4.5,9.1$ & $3.1,6.4$ & $3.7,7.6$ \\
\hline
\end{tabular}

Note: IOP data in $\mathrm{mmHg}$.

Abbreviations: IOP, intraocular pressure; SD, standard deviation; SEM, standard error of mean; Cl, confidence interval. 


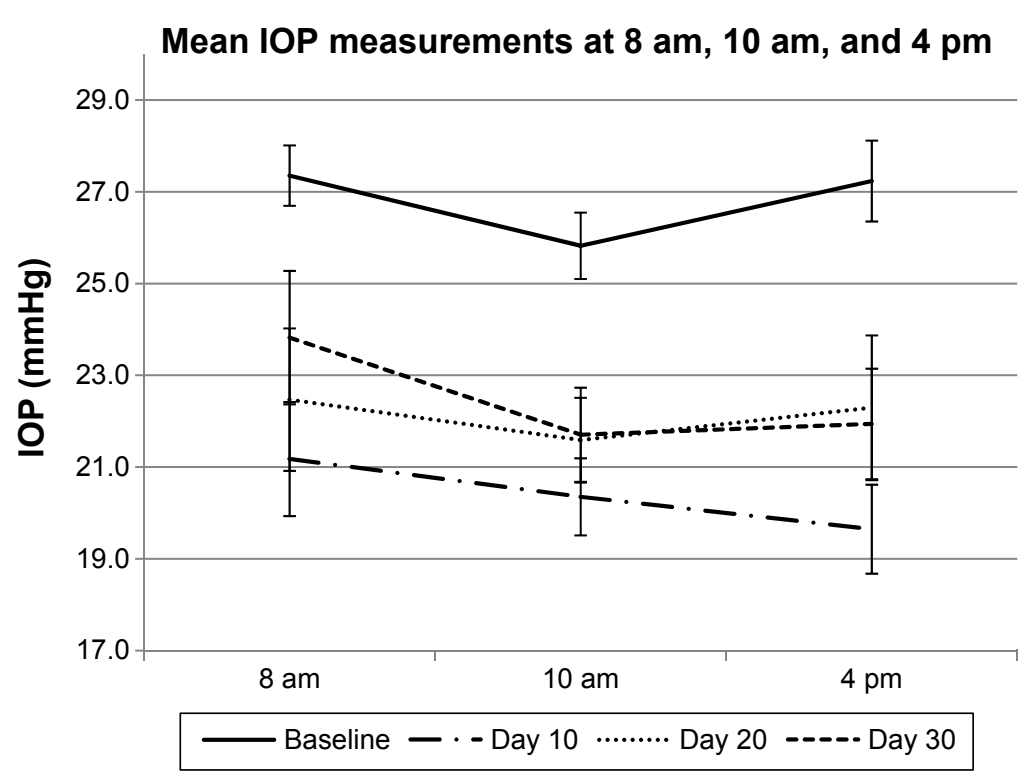

Figure 2 Mean IOP of the study patients $(\mathrm{N}=17)$ at different time points for each study visit. Abbreviation: IOP, intraocular pressure.

Table 4 Changes in IOP at the follow-up visits following OTX-TP insertion

\begin{tabular}{llllll}
\hline & Baseline (N=I7) & Day 3 (N=I7) & Day I0 (N=I7) & Day 20 (N=I7) & Day 30 (N=I7) \\
\hline Mean (SD) & $26.80(2.48)$ & $21.4 I(5.16)$ & $20.39(3.52)$ & $22.12(4.94)$ & $22.49(4.55)$ \\
Median & 26.00 & 22.00 & 19.67 & 20.67 & 22.00 \\
Mean difference from baseline (SD) & & $5.39(4.53)$ & $6.41(2.93)$ & $4.69(5.31)$ & $4.31(4.87)$ \\
95\% Cl of the difference & & $3.06,7.72$ & $4.90,7.92$ & $1.95,7.42$ & $1.81,6.82$ \\
Mean percentage drop from baseline & & 20.3 & 24.0 & 17.0 & 15.6 \\
-value $^{\text {a }}$ & & 0.001 & $<0.001$ & 0.004 & 0.004 \\
\hline
\end{tabular}

Note: ${ }^{a} A$-value of $<0.01$ was considered statistically significant after pairwise comparison using Wilcoxon signed ranks paired test.

Abbreviations: IOP, intraocular pressure; OTX-TP, travoprost punctum plug; SD, standard deviation; $\mathrm{Cl}$, confidence interval.

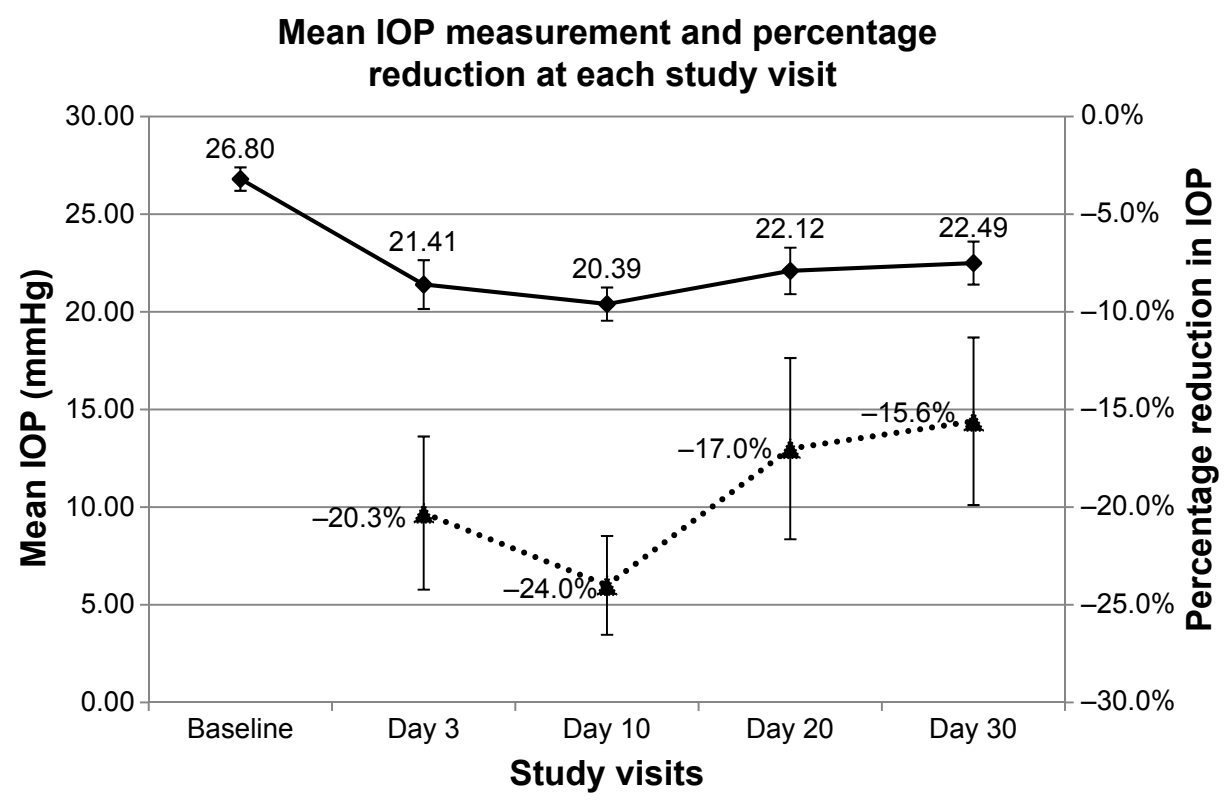

$\multimap$ Mean IOP $\cdots$-... Percentage IOP reduction

Figure 3 Mean IOP and percentage reduction in IOP in the study patients $(\mathrm{N}=17)$ at different study visits.

Abbreviation: IOP, intraocular pressure. 
Table 5 Numbers of subjects achieving targets of IOP lowering at the follow-up visits following OTX-TP insertion

\begin{tabular}{lllll}
\hline & $\begin{array}{l}\text { Day 3, } \\
\text { N (\%) }\end{array}$ & $\begin{array}{l}\text { Day I0, } \\
\mathbf{N ~ ( \% ) ~}\end{array}$ & $\begin{array}{l}\text { Day 20, } \\
\mathbf{N}(\%)\end{array}$ & $\begin{array}{l}\text { Day 30, } \\
\mathbf{N}(\%)\end{array}$ \\
\hline$\leq 15 \mathrm{mmHg}$ & $\mathrm{I}(5.9)$ & 0 & 0 & 0 \\
$\leq 18 \mathrm{mmHg}$ & $5(29.4)$ & $4(23.5)$ & $6(35.3)$ & $3(17.6)$ \\
$\leq 21 \mathrm{mmHg}$ & $8(47.1)$ & $\mathrm{II}(64.7)$ & $10(58.8)$ & $8(47.1)$ \\
$\geq 20 \%$ reduction & $7(41.2)$ & $\mathrm{II}(64.7)$ & $8(47.1)$ & $7(41.2)$ \\
$\geq 30 \%$ reduction & $5(29.4)$ & $6(35.3)$ & $4(23.5)$ & $3(17.6)$ \\
\hline
\end{tabular}

Abbreviations: IOP, intraocular pressure; OTX-TP, travoprost punctum plug.

IOP lowering observed in the majority of patients, one cannot determine whether the residual IOP-lowering effect was from undetected remnants of OTX-TP or from residual travoprost after the OTX-TP had been excreted.

Only one subject required removal of the OTX-TP on day 1 due to epiphora. This gave a nontolerance rate of only $1 / 17$, meanwhile the low hyperemia scores $(0.1$ out of 3 for severity, Table 8 ) are better than the $33 \%$ of hyperemia noted on meta-analysis of travoprost clinical trials. ${ }^{11}$ However, this was a pilot study with relatively small sample size and short duration, and hence, a larger long-term study may need to be conducted to evaluate the patient acceptability, considering that other local side effects such as lash growth and skin discoloration and dry eye are more common after prolonged use of travoprost. The ocular complaints tended to peak at 3 days and disappeared at day 30 , at which point only two subjects complained of itching and one had tearing.

From previous Phase III studies in the literature, travoprost monotherapy used once at night has been found to lower IOP by $6.5-9.0 \mathrm{mmHg}$ from baseline, with an IOPlowering effect of $19 \%-29 \%$ at 6 months. ${ }^{11}$ It is noteworthy that the OTX-TP demonstrated a comparable IOP-lowering effect (24\%) at 10 days while all the plugs were still present, with slightly lower IOP reduction at 30 days, most probably related to retention issues. One might expect that diurnal IOP variation from the peaks and troughs seen with topical administration may be smoothed out by the sustained-release

Table 6 Reconciliation of OTX-TP (total OTX-TP insertions =26)

\begin{tabular}{llllll}
\hline & \multicolumn{6}{l}{ Visit day } \\
\cline { 2 - 6 } & $\mathbf{0}$ & $\mathbf{3}$ & $\mathbf{1 0}$ & $\mathbf{2 0}$ & $\mathbf{3 0}$ \\
\hline $\begin{array}{l}\text { Removal of plug } \\
\text { due to intolerability }\end{array}$ & 0 & $2^{\mathrm{a}}$ & 0 & 0 & 0 \\
$\begin{array}{l}\text { Switching to drops } \\
\text { Retention of OTX-TP by }\end{array}$ & 0 & $2^{\mathrm{a}}$ & 0 & $\mathrm{I}$ & $\mathrm{I}$ \\
visualization & $26 / 26$ & $100 \%$ & $100 \%$ & $87.5 \%$ & $41.7 \%$ \\
\hline
\end{tabular}

Notes: an day 3, two OTX-TP plugs were removed from one patient, and the patient was restarted on topical ocular hypotensives due to intolerability.

Abbreviations: IOP, Intraocular pressure; OTX-TP, travoprost punctum plug. pharmacokinetics. At 10 days, the mean IOP (standard error of mean) was 21.2 (1.2), 20.4 (0.8), and 19.7 (1.0) at $8 \mathrm{am}, 10 \mathrm{am}$, and $4 \mathrm{pm}$, respectively, showing no discernible IOP trend during the course of the day. This study did not reveal any diurnal trend at any time point, showing a similarly narrow diurnal variation throughout the 30 days (Figure 2).

Apart from the sustained IOP-lowering effect, the strengths of the OTX-TP include its atraumatic ease of insertion and paucity of adverse events. However, the uptake and acceptability of this device by patients will depend on physician and patient attitudes toward receiving sustainedrelease medications in this format, compared to the established method of topical drops. Some patients may have issues with the retention or the placement of punctual plugs for the treatment of dry eye, and so will not be considered as candidates for the use of OTX-TP as a sustained-release device, limiting the applicable population for this plug-based drug delivery system.

The transillumination method to determine plug retention of violet-colored plugs proved to be difficult and probably underestimated plug retention, based on the lack of corresponding IOP increase. Labeling the plug with a more obvious fluorescent dye that persists throughout the treatment period will vastly improve visualization in situ. With this, patients themselves might be able to self-assess the OTX-TP presence. Future work will include increasing the maximum period of drug delivery. Longer durations will require greater drug loading to deliver a comparable elution rate of drug over the extended time course. Retention rate improvement efforts should concentrate on optimization of the OTX-TP dimensions and swelling mechanism. Attention should also be paid to assessing the attitudes and acceptance of such a device among patients with glaucoma.

Our study had several limitations. First, the small sample size and the absence of a control group (eg, topical travoprost nocte) preclude more robust conclusions; however, as a pilot feasibility study, the results were promising. Second, the results may not be generalizable to populations where additional topical therapy such as lubricants or other ocular hypotensives are being used alongside the OTX-TP, due to the potential for altered pharmacokinetics from dilution. This is particularly relevant, as studies have shown that almost $40 \%$ of patients require additional therapies to control IOP. ${ }^{10}$ Finally, the results of this study performed on an Asian population may not be extrapolated across other ethnicities, as there may be differences in eyelid anatomy for insertion and retention or in patients' responses. The 30-day period 


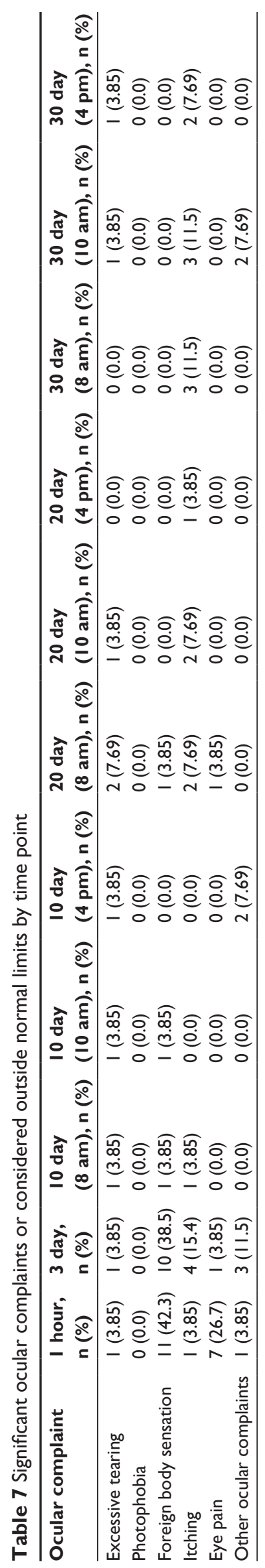

Table 8 Mean ocular hyperemia and change from baseline scored from 0 (none) to 3 (severe)

\begin{tabular}{lll}
\hline Days & Mean & Change from baseline \\
\hline Baseline & 0.7 & \\
Day 3 & 1.2 & 0.5 \\
Day 10 & 0.8 & 0.1 \\
Day 20 & 0.8 & 0.1 \\
Day 30 & 0.8 & 0.1 \\
\hline
\end{tabular}

of investigation may be too short to elicit potential longer term concerns about harboring a prostaglandin analog continuously within the punctum or even problems relating to multiple punctal insertions.

In summary, this initial feasibility trial of the OTX-TP demonstrated significant IOP reduction of up to $24 \%$ from baseline over a 1-month period, combined with good retention and low adverse events. It is a potentially well-tolerable ocular hypotensive for glaucoma patients, especially for those with a history of poor compliance.

\section{Disclosure}

The study was supported by Ocular Therapeutix, Bedford, MA, USA. Dr Aung has been a Consultant to Alcon, Allergan, Bausch \& Lomb, MSD, and Quark; Dr Paul Chew has received research support from Alcon, Allergan, Aquesys, Carl Zeiss Meditec and Ellex; and travel support/ honoraria from Alcon, Allergan, Ellex, MSD, Pfizer, and Santen. Dr Perera has received honoraria from Pfizer and Allergan. The authors report no other conflicts of interest in this work.

\section{References}

1. Schwartz GF, Quigley HA. Adherence and persistence with glaucoma therapy. Surv Ophthalmol. 2008;53(Suppl 1):S57-S68.

2. Mansouri K, Iliev ME, Rohrer K, Shaarawy T. "Compliance and knowledge about glaucoma in patients at tertiary glaucoma units." Int Ophthalmol. 2011;31:369-376.

3. Friedman DS, Quigley HA, Gelb L, et al. Using pharmacy claims data to study adherence to glaucoma medications: methodology and findings of the glaucoma and adherence and persistency study (GAPS). Invest Ophthalmol Vis Sci. 2007;48:5052-5057.

4. Quek DT, Ong GT, Perera SA, Lamoureux EL, Aung T. Persistence of patients receiving topical glaucoma monotherapy in an Asian population. Arch Ophthalmol. 2011;129:643-648.

5. Fiscella RG, Lee J, Davis EJ, Walt J. Cost of illness of glaucoma: a critical and systematic review. Pharmacoeconomics. 2009;27:189-198.

6. Riva I, Katsanos A, Floriani I, et al. Long-term 24-hour intraocular pressure control with travoprost monotherapy in patients with primary open-angle glaucoma. J Glaucoma. 2014;23(8):535-540.

7. Quaranta L, Riva I, Katsanos A, Floriani I, Centofanti M, Konstas AG. Safety and efficacy of travoprost solution for the treatment of elevated intraocular pressure. Clin Ophthalmol. 2015;9:633-643.

8. Denis P, Covert D, Realini A. Travoprost in the management of openangle glaucoma and ocular hypertension. Clin Ophthalmol. 2007;1: $11-24$. 
9. Anderson DR, Patella VM. Automated Static Perimetry. 2nd ed. Vol 363. St Louis, MO: Mosby; 1999.

10. Honrubia F, García-Sánchez J, Polo V, de la Casa JM, Soto J. Conjunctival hyperaemia with the use of latanoprost versus other prostaglandin analogs in patients with ocular hypertension or glaucoma: a meta-analysis of randomized clinical trials. Br J Ophthalmol. 2009;93:316-321.
11. Kass MA, Heuer DK, Higginbotham EJ, et al. The ocular hypertension treatment study: a randomized trial determines that topical ocular hypotensive medication delays or prevents the onset of primary openangle glaucoma. Arch Ophthalmol. 2002;120:701-713.

\section{Publish your work in this journal}

Clinical Ophthalmology is an international, peer-reviewed journal covering all subspecialties within ophthalmology. Key topics include: Optometry; Visual science; Pharmacology and drug therapy in eye diseases; Basic Sciences; Primary and Secondary eye care; Patient Safety and Quality of Care Improvements. This journal is indexed on

\section{Dovepress}

PubMed Central and CAS, and is the official journal of The Society of Clinical Ophthalmology (SCO). The manuscript management system is completely online and includes a very quick and fair peer-review system, which is all easy to use. Visit http://www.dovepress.com/ testimonials.php to read real quotes from published authors. 